\title{
Highly Reproducible Techniques for Use in Systematic Bacteriology in the Genus Mycobacterium: Tests for Pigment, Urease, Resistance to Sodium Chloride, Hydrolysis of Tween 80 , and $\beta$-Galactosidase
}

L. G. WAYNE, H. C. ENGBAEK, H. W. B. ENGEL, S. FROMAN, W. GROSS, J. HAWKINS, W. KÄPPLER, A. G. KARLSON, H. H. KLEEBERG, I. KRASNOW, G. P. KUBICA, C. MCDURMONT, E. E. NEL, S. R. PATTYN, K. H. SCHRÖDER, S. SHOWALTER, I. TARNOK, M. TSUKAMURA, B. VERGMANN, and E. WOLINSKY

Veterans Administration Hospital, Long Beach, California 90801; California College of Medicine, University of California, Irvine, California 92664; Statens Seruminstitut, Copenhagen, $S$. Denmark; Rijks Instituut Voor de Volksgezondheid, Utrecht, Holland; Olive View Medical Center, Sylmar, California 91342; Veterans Administration Hospital, West Haven, Connecticut 06516; Tuberkulose-Forschungsinstitut, Berlin, West Germany; Mayo Clinic, Rochester, Minnesota 55901; Tuberculosis Research Unit, Onderstepoort, Republic of South Africa; Trudeau Institute, Inc. Saranac Lake, New York 12983; Department of Public Health, Montgomery, Alabama 36104; Instituut Voor Tropische Geneeskunde, Antwerpen, Belgium; Forschunginstitut, Borstel, West Germany; National Sanatorium, Chubu Chest Hospital, Obu Chita-Gun Aichi-Ken, Japan; and Cuyahoga County Hospital, Cleveland Metropolitan General Hospital, Cleveland, Ohio 44109

The International Working Group on Mycobacterial Taxonomy has undertaken a series of cooperative studies to standardize and establish reproducibility of tests that are useful for classifying and identifying mycobacteria. To date 25 techniques have been examined, and 5 of these met our rigorous criteria for reproducibility and differential power. The properties determined by these tests are urease activity, pigment production, tolerance to $5 \% \mathrm{NaCl}$, hydrolysis of Tween 80 , and $\beta$-galactosidase activity.

The International Working Group on Mycobacterial Taxonomy (IWGMT) is an informal confederation of investigators who have undertaken a series of cooperative studies into the taxonomy of the genus Mycobacterium $(3,6)$. The members also serve in an advisory capacity to the Subcommittee on Mycobacterium of the International Committee for Systematic Bacteriology. The data derived from the cooperative studies have not only contributed to a definition of species (clusters) of the mycobacteria, but have identified those properties that are most definitive of species and, thus, of the greatest potential determinative value. However, these investigations were conducted under a permissive philosophy, with each participant free to select the specific technique to be employed for determining a given property. The principles and logistics of the IWGMT studies have been discussed previously (6).

To contribute to greater standardization of methods applied to the systematic bacteriology of mycobacteria, a new series of studies has been undertaken to evaluate the reproducibility of specific techniques. This is a report on the first IWGMT pilot cooperative study of standardization of techniques for use with slowly growing mycobacteria.

\section{MATERIALS AND METHODS}

Selection of tests for study. The tests were chosen on the basis of prior cooperative studies of the IWGMT that dealt with slowly growing mycobacteria. These cooperative studies were concerned with the taxonomy of scotochromogens of Runyon group II (6), non-photochromogens of group III (Meissner et al., J. Gen. Microbiol., in press), photochromogens of group I (Tacquet et al., manuscript in preparation), and members of the $M$. tuberculosis-M. bovis complex (Kleeberg et al., manuscript in preparation). Characters were defined as of potential systematic value if over $85 \%$ of the strains of one or more cluster recognized in these studies exhibited the character and if over $85 \%$ of the strains of one or more of the remaining clusters failed to exhibit the character.

A total of 69 characters, derived from 25 tests, met the criteria defined above. Participants in the prior cooperative studies were asked to provide details of the techniques they had employed, and from these responses a working manual was developed in which the techniques were described in detail. 
Cultures. The 18 cultures listed in Table 1 were selected from a collection that had been deposited previously with the American Type Culture Collection and distributed to members who had agreed to perform some or all of the selected tests. No attempt was made to select strains that were most characteristic of their species. On the contrary, some atypical strains were included to provide a broad range of reaction patterns.

Participation. Participants were not required to perform all of the tests described in the working manual. They were, however, to examine all 18 cultures by the tests they had elected to perform. Participants were asked to perform each test three times on each strain, if possible. The tests were to be carried out exactly as described in the working manual. Data were submitted to the study coordinator (L. G. Wayne) for transcription and analysis.

The descriptions of techniques for five of the tests which were evaluated are presented below, since the present authors believe that they yield highly reproducible data with taxonomic and determinative value.

Urease (1; Bönicke, personal communication)

\section{Media and reagents}

a. Löwenstein-Jensen (L-J) egg medium is prepared according to conventional formulation. (Minor differences in ingredients available to the participants did not appear to detract from the reproducibility of this test.)

TABLE 1. Cultures examined in the cooperative study ${ }^{a}$

\begin{tabular}{|c|c|c|}
\hline ATCC no. & Culture label & Comments \\
\hline 12478 & $\begin{array}{l}\text { Mycobacterium } \\
\text { kansasii }\end{array}$ & \\
\hline 14470 & M. gordonae & \\
\hline 14474 & M. flavescens & \\
\hline 19981 & M. scrofulaceum & \\
\hline 23285 & $M$. gordonae & Ureolytic strain \\
\hline 23292 & M. triviale & \\
\hline 23432 & $\begin{array}{l}\text { Mycobacterium } \\
\text { spp. }\end{array}$ & $\begin{array}{l}\text { Scotochromogen, } \\
\text { see ref. (6) }\end{array}$ \\
\hline 25039 & $M$. marinum & \\
\hline 25041 & M. kansasii & \\
\hline 25046 & M. kansasii & $\begin{array}{l}\text { Nonpigmented } \\
\text { strain }\end{array}$ \\
\hline 25145 & $\begin{array}{l}\text { M. nonchromo- } \\
\text { genicum }\end{array}$ & \\
\hline 25158 & M. gastri & \\
\hline 25163 & M. xenopi & \\
\hline 25167 & M. avium & \\
\hline 25169 & M. intracellulare & \\
\hline 25269 & M. terrae & \\
\hline 25275 & M. simiae & \\
\hline 27373 & M. bovis & $\mathrm{BCG}$ \\
\hline
\end{tabular}

${ }^{a}$ These cultures were not specifically selected as very typical of their species. b. The substrate solution is prepared by dissolving $10 \mathrm{mg}$ of urea in $100 \mathrm{ml}$ of sterile water, in a sterile bottle. The solution is not further sterilized and is stable for at least 2 months under refrigeration.

c. For reagent $1,67 \mathrm{mg}$ of $\mathrm{MnSO}_{4} \cdot 4 \mathrm{H}_{2} \mathrm{O}$ is dissolved in $100 \mathrm{ml}$ of distilled water. If a different hydrate of the salt is employed, the amount is adjusted accordingly. This reagent is stable indefinitely.

d. For reagent 2, $25 \mathrm{~g}$ of phenol (reagent grade) is suspended, with shaking, in $10 \mathrm{ml}$ of distilled water. A 54-ml volume of $5 \mathrm{~N} \mathrm{NaOH}$ is added with shaking, until the solution clears; then an additional $36 \mathrm{ml}$ of distilled water is added. This solution is not stable.

e. For reagent 3 , commercially available sodium hypochlorite solution (approximately $15 \% \mathrm{NaOCl}$, and containing at least $5 \%$ available chlorine) is diluted by adding 1 part to 10 parts of distilled water. This solution is stable in the refrigerator for about 4 weeks.

\section{Inoculum}

Cultures are grown on L-J medium and harvested while they are actively growing. Growth is carefully scraped from medium (avoid carrying any medium into the inoculum). The cells are weighed in a sterile tube or bottle. There must be at least $20 \mathrm{mg}$ (wet weight) of cells for this test. The weighed cells are suspended in sterile saline and centrifuged. The supernatant is discarded, and the cells are suspended in sufficient sterile $0.067 \mathrm{M}$ phosphate buffer $(\mathrm{pH} \mathrm{7.2)}$ to yield a cell concentration of $10 \mathrm{mg} / \mathrm{ml}$. A $1-\mathrm{ml}$ volume of suspension is distributed to each of two sterile test tubes. The urea substrate solution $(1 \mathrm{ml})$ is added to one tube of cell suspension and $1 \mathrm{ml}$ of sterile water is added to the other.

\section{Time and conditions of incubation}

The tubes are capped and incubated at $37 \mathrm{C}$ for 16 h. The following are added to each tube: reagent 1 , $0.1 \mathrm{ml}$; reagent $2,1.0 \mathrm{ml}$; reagent $3,0.5 \mathrm{ml}$. The rack of tubes is then placed in a $100 \mathrm{C}$ steam bath for 30 $\min$.

\section{Method of reading results}

A blue color which appears after heating of the test mixtures constitutes a positive reaction. It may be helpful to establish some arbitrary scale of degree of intensity of color (i.e., 0 to $4+$ ), but generally a result is recorded simply as positive or negative. Each time the test is run, a tube of substrate without cells should be run as a control for spontaneous hydrolysis.

\section{Special problems or pitfalls}

This test is based on a very sensitive assay for ammonia released by hydrolysis of the amides. It is essential, therefore, that ammonia-free water be used for all solutions. Avoid ammonia-laden atmospheres such as may occur in the proximity of animal rooms. 
Pigment (7, 8)

\section{Media and reagents}

L-J medium is prepared from standard formulation and dispensed in 3- to $3.5-\mathrm{ml}$ amounts to $15-\mathrm{ml}$ 'screw-capped bottles. These are laid flat and inspissated.

\section{Inoculum}

A small amount of growth is scraped from a stock culture (any medium) and suspended in distilled water. For colonies that resist suspending, Tween 80 is added to $0.02 \%$. This suspension is added dropwise to another tube of the same diluent until a very slight, barely perceptible turbidity is seen. Three drops of this dilute inoculum are placed on the surface of each of two bottles of L-J medium.

\section{Time and conditions of incubation}

The cultures are incubated with loose caps, at 25 to $30 \mathrm{C}$. One of the tubes is unshielded; the other is placed in a light-proof box beside the unshielded one. Both are placed under a "daylight" fluorescent lamp (combined wattage of 30 ) at a distance of $40 \mathrm{~cm}$. Incubation is continued until definite growth is first seen, usually about 2 weeks.

\section{Method of reading results}

When definite colonies are seen in the unshielded culture bottle, the presence or absence of pigment is noted. The shielded culture is then removed from its box, and the presence or absence of pigment is noted; this tube is then exposed to continuous light and reexamined after 8,24 , and $48 \mathrm{~h}$ for development of pigment. Several combinations of results are possible: (i) no pigment in any tube, before or after light exposure; (ii) pigment in the unshielded tube, none in the shielded one; pigment develops after exposing the shielded one to light, i.e., photochromogenicity; (iii) pigment of equal intensity in both tubes at first examination, i.e., scotochromogenicity; (iv) pigment in both tubes at first examination, but color is more intense in the unshielded one, i.e., scotochromogenicity with intensification by light. In the case of pigmented cultures, actual color should be noted, i.e., yellow, orange, pink, red, salmon, or coral.

\section{Special problems or pitfalls}

Proper development of pigment requires adequate air; be sure caps on bottles are loose throughout incubation period. Photochromogenic response may not occur in old cultures. When the unshielded culture is yellow and the shielded one is white, the shielded one should be removed from its box and exposed to light when less than 3 weeks old for confirmation of photochromogenicity. Some cultures may be erratic producers of pigment and give an impression of photochromogenicity. This is sometimes true with unusual pink or coral-colored strains, so indication of actual color seen is important, although fine distinctions of hue are not. Some cultures show no pigment when first definite growth is seen, even under continuous light exposure, but may become yellow on prolonged incubation; these are recorded as nonpigmented.

\section{Tolerance to $5 \%$ sodium chloride (2)}

\section{Media and reagents}

L-J medium is prepared from standard formulation. To $300 \mathrm{ml}$ of $\mathrm{L}-\mathrm{J}, 15 \mathrm{~g}$ of $\mathrm{NaCl}$ is added and mixed well. The medium is dispensed in $3-$ to $3.5-\mathrm{ml}$ amounts of $15-\mathrm{ml}$ screw-capped bottles. These are laid flat and inspissated. Similar slants of L-J control medium without $\mathrm{NaCl}$ are also prepared.

\section{Inoculum}

A barely turbid suspension of cells is prepared as described for the test for pigment production. A $0.1-\mathrm{ml}$ volume of this dilute suspension is added to 10 $\mathrm{ml}$ of sterile water, and 3 drops each of this very dilute suspension are inoculated to a bottle of L-J with $5 \%$ $\mathrm{NaCl}$ and to a bottle of L-J control medium.

\section{Time and conditions of incubation}

Cultures are incubated with loose caps at $35 \mathrm{C}$. When surface moisture has evaporated, the caps may be tightened. Cultures need be incubated no longer than 6 weeks.

\section{Method of reading results}

Time of first definite growth on L-J control is noted. The inoculum described should ultimately yield innumerable colonies or confluent growth. The $\mathrm{NaCl}$ L-J bottles are examined weekly for 3 weeks after the first appearance of growth on control medium. If more than 50 colonies are seen in that time on the $\mathrm{NaCl}$ medium, the culture is recorded as tolerant if fewer than 50 colonies develop, it is sensitive.

\section{Hydrolysis of Tween 80 (8)}

\section{Media and reagents}

A 500-mg amount of Tween 80 (polyoxyethylene sorbitan monooleate) and $2.0 \mathrm{mg}$ of neutral red are dissolved in $100 \mathrm{ml}$ of $0.067 \mathrm{M}$ phosphate buffer $(\mathrm{pH}$ 7.0). The solution is dispensed in 4-ml amounts to screw-capped test tubes (16 by $125 \mathrm{~mm}$ ) and 
autoclaved for $15 \mathrm{~min}$ at $121 \mathrm{C}$. It is critical that the solution contain the full amount of actual neutral red dye specified. Inasmuch as many batches of dye are less than $100 \%$ pure, a correction should be made in weighing out the dye to compensate for the impurity present. For example, if the label on the batch being used indicates an $80 \%$ dye content, it would be necessary to use $100 / 80 \times 2.0$, or $2.5 \mathrm{mg}$, of the impure dye to get a true $2.0 \mathrm{mg}$ of neutral red. The Tween neutral red solutions must be kept refrigerated and protected from light. Prolonged exposure to light causes the dye to fade.

\section{Inoculum}

A large loop of growth is scraped from an actively growing culture on solid medium and suspended well in a tube of Tween-neutral red reagent solution. The final concentration of cells should be between 1 and $10 \mathrm{mg}$ (moist weight) per $\mathrm{ml}$.

\section{Time and conditions of incubation}

The suspension is incubated in the dark at $35 \mathrm{C}$ for 10 days. It is removed and read daily; the tube is shaken briefly after each examination.

\section{Method of reading results}

The tubes are held up to a fluorescent desk lamp, with the top level of fluid just against the light shield. The solution is viewed at such an angle that the eye is not in a direct line with the light, but slightly above the light shield. Uninoculated reagent and suspensions of cultures that fail to hydrolyze Tween 80 are an amber-yellow color. Hydroly sis of Tween 80 results in a gradual change of color from pale salmon, to pink, and of ten to bright red. The first definite change to the salmon color is the positive reaction. The day when this occurs is noted and the incubation is continued to confirm deepening of the pink color. Results are expressed as positive within 5 days, positive within 10 days, and negative after 10 days.

\section{Special problems or pitfalls}

The need for full dye concentration and protection from light was discussed above. One should also be aware that it is the color of the solution one is interested in, not the color of the suspended cells. Some cells may take up the dye and the sediment will appear pink, but if the supernatant is amber, the test is negative. This is the reason the tubes should not be shaken until after each daily reading.

$\beta$-Galactosidase (E. Kubala, personal communication)

\section{Media and reagents}

a. Modified Dubos medium base containing: $\mathrm{KH}_{2}$ $\mathrm{PO}_{4}, 1.0 \mathrm{~g} ; \mathrm{Na}_{2} \mathrm{HPO}_{4} \cdot 12 \mathrm{H}_{2} \mathrm{O}, 6.25 \mathrm{~g} ; \mathrm{MgSO} 4 \cdot 7 \mathrm{H}_{2} \mathrm{O}$,
$0.6 \mathrm{~g}$; sodium citrate, $1.5 \mathrm{~g}$; asparagine, $2.0 \mathrm{~g}$; and Tween $80,5 \mathrm{ml}$ of a $10 \%$ aqueous solution. The ingredients are dissolved separately, each in $100 \mathrm{ml}$ of water, and then combined, and the volume is brought to $1,000 \mathrm{ml}(\mathrm{pH} \mathrm{7.2)}$. The basal solution is dispensed in 100-ml amounts and autoclaved at $121 \mathrm{C}$ for 20 $\min$.

b. For the albumin solution, $9 \mathrm{~g}$ of albumin fraction $\mathrm{V}$ is dissolved in $100 \mathrm{ml}$ of saline, and the solution is heated to $56 \mathrm{C}$ for $30 \mathrm{~min}$. This solution is sterilized by filtration.

c. 2-Nitropheny l- $\beta$-D-galactopyranoside.

d. For complete medium, $100 \mathrm{mg}$ of 2-nitrophenyl$\beta$-D-galactopyranoside is dissolved in $100 \mathrm{ml}$ of modified Dubos medium base. To this is added $4 \mathrm{mi}$ of albumin solution. The complete medium is filter-sterilized and distributed aseptically in 5-ml amounts to sterile, screw-capped tubes.

\section{Inoculum}

A $0.5-\mathrm{ml}$ aqueous suspension of $1 \mathrm{mg}$ of bacteria per $\mathrm{ml}$, prepared from an actively growing L-J culture, is added to a tube of medium.

\section{Time and conditions of incubation}

Four to six weeks; 35 C.

\section{Method of reading results}

A positive reaction is indicated by the suspension turning yellow.

\section{RESULTS}

Investigators from 16 laboratories examined the test cultures and submitted data before the study cutoff date. The data were transcribed and analyzed in the following manner.

The test result obtained by a majority of participants for each strain was considered the "concensus" result for that strain. The total number of results in agreement with strain concensus obtained for a test was divided by the total number of responses submitted for that test and designated mean percent agreement.

The number of laboratories showing over $90 \%$ agreement with concensus results were also tabulated.

The number of strains yielding over $90 \%$ positive and over $90 \%$ negative results in pooled data for a given test were also tabulated.

Internal consistency of labs was determined only for those laboratories that performed tests in triplicate. The number of cultures on which triplicate results were obtained in a given test 
was designated $T$. The number of cultures in which all three replicate results were in agreement with each other was designated $C$. The mean percent internal consistency is thus $(C / T)$ $X 100$. This is not a measure of "correctness" of answer, but only of reproducibility within a lab.

It must be pointed out that the values for mean percent agreement with strain concensus in Table 2 are not strictly comparable to the scores for internal consistency within labs. In determining internal consistency of laboratories, a single disagreement among three replications was recorded as a replication failure for that set. Thus, if a laboratory examined all 18 strains in triplicate for a given test, there would have been 54 bits of data. If there was one disagreement with strain concensus, it would reduce mean agreement by one in 54 , or approximately $2 \%$. When, however, one of three replications in a single strain disagreed with the other two, that triplet was recorded as inconsistent. That is, that one set among 18 triplicate sets would reduce internal consistency by approximately $6 \%$. If the one disagreement in a triplicate set were treated as a single score rather than as a set, disregarding correctness of the response in a given laboratory, then mean internal consistency of tests would have ranged from 97 to $99 \%$, and the range of laboratories would have been 89 to $100 \%$ for the five tests reported.
In the present report we present results only for those techniques which met all four of the following rigorous criteria. (i) Ten or more replicate data (combined from all laboratories) were received for each test strain subjected to the test. (ii) The mean percent agreement for that test was equal to or exceeded $90 \%$. (iii) At least one strain was recorded as positive in at least $90 \%$ of 10 or more replications of the test. (iv) At least one additional strain was recorded as negative in at least $90 \%$ of 10 or more replications of the test.

Eight tests met these criteria, but three of these were tests for drug susceptibility in agar. Because of discrepancies observed in results of other drug susceptibility tests and a need for uniform methods of testing susceptibility to many drugs, we are not presenting the drug susceptibility technique until further studies have been conducted. The analyses of results with the remaining five tests are presented in Tables 2, 3, and 4 .

\section{DISCUSSION}

The data on urease activity in Tables 2 and 3 are based on an average total of 25 replications per strain of bacteria. Although a very high mean percent agreement is seen in this test, a disproportionate number of the few disagreements occurred in 1 of the 11 laboratories in which this test was performed. That laboratory

TABLE 2. Reproducibility and differential consistency of five tests

\begin{tabular}{|c|c|c|c|c|c|c|c|c|c|c|}
\hline \multirow{3}{*}{ Property } & \multicolumn{4}{|c|}{$\begin{array}{l}\text { Agreement with } \\
\text { strain concensus }\end{array}$} & \multicolumn{2}{|c|}{$\begin{array}{l}\text { No. of } \\
\text { strains } \\
\geqq 90 \%\end{array}$} & \multicolumn{4}{|c|}{$\begin{array}{l}\text { Internal } \\
\text { consistency } \\
\text { of labs }\end{array}$} \\
\hline & \multirow{2}{*}{$\begin{array}{l}\frac{0}{0} \\
\dot{0} \\
\dot{0} \\
\dot{z}\end{array}$} & \multirow{2}{*}{ 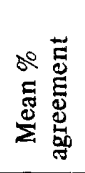 } & \multirow{2}{*}{ 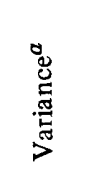 } & \multirow{2}{*}{ 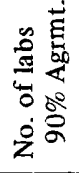 } & \multirow{2}{*}{ 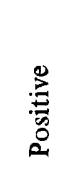 } & \multirow{2}{*}{ 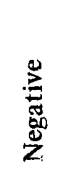 } & \multirow[b]{2}{*}{ 它 } & \multirow{2}{*}{ 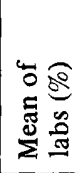 } & \multicolumn{2}{|c|}{$\begin{array}{l}\text { Range } \\
\text { of labs }\end{array}$} \\
\hline & & & & & & & & & Low & High \\
\hline Urease & 11 & 96.7 & 0.034 & 10 & 10 & 7 & 7 & 93 & 72 & 100 \\
\hline Pigment & 13 & 93.4 & 0.068 & 9 & $b$ & $b$ & 10 & 92 & 69 & 100 \\
\hline Growth on $5 \% \mathrm{NaCl}$ & 13 & 92.1 & 0.081 & 9 & 1 & 10 & 10 & 95 & 67 & 100 \\
\hline $\begin{array}{r}\text { Tween } 80 \text { hydrolysis, } 5 \text { day } \\
10 \text { day }\end{array}$ & $\begin{array}{l}15 \\
15\end{array}$ & $\begin{array}{l}90.0 \\
95.7\end{array}$ & $\begin{array}{l}0.101 \\
0.052\end{array}$ & $\begin{array}{r}7 \\
13\end{array}$ & $\begin{array}{r}7 \\
11\end{array}$ & $\begin{array}{l}4 \\
4\end{array}$ & $\begin{array}{l}11 \\
11\end{array}$ & $\begin{array}{l}95 \\
.96\end{array}$ & $\begin{array}{l}83 \\
89\end{array}$ & $\begin{array}{l}100 \\
100\end{array}$ \\
\hline$\beta$-Galactosidase & 6 & 90.0 & 0.107 & 5 & 2 & 7 & 3 & 96 & 93 & 100 \\
\hline
\end{tabular}

${ }^{a}$ Variance $\left(s_{1}{ }^{2}\right)$ was calculated from formula 14 of Sneath and Johnson (5). The value for degrees of freedom $(N-1)$ in that formula were based on average values of $N$ per strain for each test since not all strains were subjected to exactly the same number of replications for a given test.

$b$ Pigment was expressed as photochromogenic (P), scotochromogenic (S), or nonchromogenic $(\mathrm{N})$, rather than as positive or negative. Two strains were $\geqq 90 \% \mathrm{P}$, four strains were $\geqq 90 \% \mathrm{~S}$, and eight strains were $\geq 90 \% \mathrm{~N}$. 
TABLE 3. Distribution of replicate test responses by culture

\begin{tabular}{|c|c|c|c|c|c|c|c|c|}
\hline \multirow[b]{3}{*}{ ATCC no. } & \multicolumn{8}{|c|}{ Replications $(\%)$ positive for: } \\
\hline & \multirow[b]{2}{*}{ Urease } & \multicolumn{3}{|c|}{ Pigment } & \multirow[b]{2}{*}{$\begin{array}{c}5 \% \\
\mathrm{NaCl}\end{array}$} & \multicolumn{2}{|c|}{ Tween hydrolysis } & \multirow[b]{2}{*}{$\begin{array}{l}\beta-\text { Galac- } \\
\text { tosidase }\end{array}$} \\
\hline & & $\begin{array}{l}\text { Photo- } \\
\text { chromogenic }\end{array}$ & $\begin{array}{c}\text { Scoto- } \\
\text { chromogenic }\end{array}$ & $\begin{array}{c}\text { Non- } \\
\text { chromogenic }\end{array}$ & & 5 Day & 10 Day & \\
\hline 27373 & 95 & 0 & 0 & 100 & 0 & 3 & 12 & 9 \\
\hline 25158 & 95 & 0 & 0 & 100 & 16 & 100 & 100 & 18 \\
\hline 12478 & 100 & 100 & 0 & 0 & 0 & 100 & 100 & 14 \\
\hline 25046 & 100 & 0 & 0 & 100 & 0 & 100 & 100 & 14 \\
\hline 25041 & 100 & 0 & 100 & 0 & 3 & 88 & 100 & 0 \\
\hline 25039 & 100 & 93 & 7 & 0 & 25 & 91 & 100 & 0 \\
\hline 25275 & 96 & 80 & 3 & 17 & 11 & 42 & 60 & 21 \\
\hline 23285 & 100 & 10 & 90 & 0 & 9 & 49 & 87 & 18 \\
\hline 14470 & 96 & 0 & 94 & 6 & 0 & 98 & 100 & 21 \\
\hline 14474 & 97 & 0 & 100 & 0 & 18 & 84 & 92 & 14 \\
\hline 25145 & 0 & 0 & 0 & 100 & 29 & 100 & 100 & 100 \\
\hline 25269 & 0 & 0 & 0 & 100 & 14 & 88 & 98 & 100 \\
\hline 23292 & 7 & 0 & 0 & 100 & 97 & 93 & 100 & 0 \\
\hline 23432 & 0 & 14 & 77 & 9 & 0 & 89 & 97 & 14 \\
\hline 19981 & 100 & 11 & 86 & 3 & 14 & 5 & 7 & 0 \\
\hline 25169 & 19 & 20 & 0 & 80 & 3 & 0 & 0 & 0 \\
\hline 25167 & 8 & 0 & 10 & 90 & 0 & 0 & 0 & 0 \\
\hline 25163 & 4 & 0 & 7 & 93 & 3 & 11 & 11 & 36 \\
\hline
\end{tabular}

TABLE 4. Distribution of disagreements in interpretation of pigment

\begin{tabular}{l|c|c|c|c|c}
\hline \multirow{2}{*}{$\begin{array}{c}\text { Concensus } \\
\text { interpretation }\end{array}$} & \multirow{2}{*}{$\begin{array}{c}\text { No. of } \\
\text { strains }\end{array}$} & $\begin{array}{c}\text { Total no. } \\
\text { of entries }\end{array}$ & $\begin{array}{c}\text { Photo- } \\
\text { chromogenic }\end{array}$ & $\begin{array}{c}\text { Scoto- } \\
\text { chromogenic }\end{array}$ & $\begin{array}{c}\text { Non- } \\
\text { chromogenic }\end{array}$ \\
\cline { 4 - 6 } & 3 & 99 & 91 & 3 & 6 \\
Photochromogenic & 6 & 204 & 6 & 91 & 3 \\
Notochromogenic & 9 & 285 & 2 & 2 & 96 \\
\hline
\end{tabular}

had a mean agreement with concensus in this test of $87 \%$ and contributed $12 \%$ of the urease data in the tables, but accounted for $47 \%$ of the total disagreements. The remaining 10 laboratories had a mean agreement of $98.0 \%$. For only one strain (25169) was there a mean agreement of less than $90 \%$.

The data on pigment are based on an average total of 33 replications per strain. One of the 13 laboratories performing this test had a mean agreement score of only $78 \%$ and contributed only $7.7 \%$ of the data on this test, but accounted for $25.6 \%$ of the total disagreements. The strains that, on concensus, were nonchromogenic accounted for only about half as many disagreements, proportionately, as did the concensus photochromogens or scotochromogens (Table 4).

The data on growth on $5 \% \mathrm{NaCL}$ are based on an average total of 34 replications per strain. Three laboratories contributed $25 \%$ of the data, but accounted for $72 \%$ of the total disagreements. The remaining 10 laboratories had a mean agreement of $97.1 \%$. The mean agreement with concensus was less than $90 \%$ for seven strains.

The data on hydrolysis of Tween 80 are based on an average total of 38 replications per strain. The criterion for a positive reaction in this test was originally the appearance of a color change after 5 days of incubation (8). However, it was found that when the cutoff date was selected at 10 days instead of 5 , nine strains yielded higher mean agreement scores, and only two had lower scores. The overall mean agreement was $5.7 \%$ higher when the criterion for positivity was a color change after 10 days (Table 2). Only one strain, 25275, yielded highly variable results by either criterion. At 10 days, this strain contributed only $5.8 \%$ of the data for this test, but accounted for $53 \%$ of the disagreements. On the other hand, 
eight strains were $100 \%$ positive by day 10 and two strains were negative in $100 \%$ of the reports at this time. The mean agreement with 10-day concensus was less than $90 \%$ for only three strains.

The data on $\beta$-galactosidase are based on an average total of 13 replications per strain. One laboratory, which contributed $15 \%$ of the data on the test, had a mean agreement of only $56 \%$ and accounted for $67 \%$ of the disagreements. The remaining five laboratories had a mean agreement of $96.1 \%$. The mean agreement with concensus was less than $90 \%$ for nine strains.

Because of the limited number of strains employed, taxonomic inferences may not be made from the results of this study. Furthermore, the fact that a test yielded poor reproducibility cannot be taken as indication that the test is unsatisfactory; one may not even conclude that the particular detailed technique was not optimal for the given character. The only definitive positive statements that can be made are those concerning tests that did yield very producible results in a number of participating laboratories.

There are a number of possible sources of disagreement (error?) in a study of the kind reported here. For convenience, they may be classified into the following four types.

Type 1 consisted of labeling errors and cross-contamination of cultures. Such errors are obviously not inherent in the tests themselves. On examination of distribution and reproducibility of errors in tests as straightforward as pigment production, there is reason to believe that such errors did occur and contribute to lowering mean agreement scores. Therefore, many of the tests in the study are probably more reliable than they appeared in this analysis.

Type 2 consisted of deviations in performance of the test due either to inexperience with the test procedure or careless errors in performance. Some participants were experienced in performing most of the tests, and others were performing certain tests for the first time. The simpler tests are straightforward enough that experience plays only a small role in performance, whereas others require more skill. In general, young, actively growing bacteria should be used for all tests.

Type 3 consisted of variability in certain strains or species. Many of the tests included in this study had mean percent agreement scores too low to permit them to meet the rigorous criteria for inclusion in this report, but did show very high resolving pewer between certain pairs of strains. In those cases, the low mean percent agreement suggests that some strains (or probably some species) are characterized by a high degree of variability in the test in question. This could reflect, for example, different degrees of uniformity in permeability and/or rates and conditions of enzyme induction. Other species may be very uniform in response to the given test. It is probably unrealistic to hope to find a series of tests (and techniques and conditions for performing them) that will provide uniform results for all species in the genus Mycobacterium. Thus, a given test may represent information in some cases and noise (6) in others, and application of a carefully assembled series of tests could provide enough information for a consistent numerical taxonomic analysis of the genus.

Type 4 consisted of variability inherent in the technique due to unknown and uncontrolled factors that affect test responses of most or all organisms. Basic studies are needed into the mechanisms of the various tests to at least provide an understanding of the reasons for variability of some strains or species.

The analyses of the five tests described in detail in this report were based on between 240 and 689 bits of data per test. All five of them had a mean reproducibility of $90 \%$ or better. On the basis of a mathematical model, Sneath and Johnson (5) have concluded that a probability of error exceeding $10 \%$ for a test is unacceptably large for numerical taxonomic use. In view of these criteria and of the demonstrated differential power of these tests in prior cooperative studies, it is recommended that the five tests described in this paper be included in a list of minimal standards for members of the genus Mycobacterium in accord with the proposed revision of the International Code of Nomenclature of Bacteria (4).

Nineteen tests, in addition to the five described, had mean agreement scores equal to or greater than $90 \%$ but failed to meet other criteria for inclusion in this report. Some of the tests might have been included if more replicate data were available. In other cases, it appeared that the restricted selection of organisms tested excluded tests that might be highly definitive for a single species (e.g., niacin test). Future studies are planned, or have been initiated, in which broader representation of cultures, greater replication, and some modifications in test procedures will be assured. It is anticipated that a battery of highly reproducible tests will be defined which will permit greater confidence to be placed in numerical taxonomic analysis of mycobacteria than has been possible to date. Furthermore, availability of such standardized 
tests should permit more efficient identification of individual isolates and thus contribute to diagnosis and to our knowledge of epidemiology of mycobacterial disease.

Some of the participants in this study objected to certain details of the techniques presented in this report, primarily on the basis of practicality of performance of certain procedures in routine laboratory use. Specifically there were objections to the need for weighing inocula and for a 16-h incubation period in the urease test. It is anticipated that modifications will frequently be proposed for test performance, especially for those tests that are most useful for routine determinative studies in clinical practice. The five techniques described here can serve as standards against which such modifications can be evaluated before adoption in a given laboratory. It should be mentioned that the IWGMT has initiated a study to determine comparability of turbidimetric and gravimetric standardization of inoculum suspensions with a variety of mycobacteria.

\section{ACKNOWLEDGMENTS}

We are grateful to Erwin Lessel for distribution of cultures.

Harriet Hunter and Anita Reynolds performed the demanding task of transcribing and tabulating over 20,000 bits of data generated in this study.

\section{REPRINT REQUESTS}

Address reprint requests to: Dr. L. G. Wayne, Veterans Administration Hospital, 5901 East Seventh St., Long Beach, California 90801.

\section{LITERATURE CITED}

1. Bönicke, R. 1962. Identification of mycobacteria by biochemical methods. Bull. Int. Union Tuberc. 32:13-68.

2. Kestle, D. G., V. D. Abbott, and G. P. Kubica. 1967. Differential identification of Mycobacteria. II. Subgroups of Groups II and III (Runyon) with different clinical significance. Amer. Rev. Resp. Dis. 95: 1041-1052.

3. Kubica, G. P., I. Baess, R. E. Gordon, P. A. Jenkins, J. B. G. Kwapinski, C. McDurmont, S. R. Pattyn, H. Saito, V. Silcox, J. L. Stanford, K. Takeya, and M. Tsukamura. 1972. A co-operative numerical analysis of rapidly growing mycobacteria. J. Gen. Microbiol. 73:55-70.

4. Lapage, S. P., W. A. Clark, E. F. Lessel, H. P. R. Seeliger, and P. H. A. Sneath. 1973. Proposed revision of the International Code of Nomenclature of Bacteria. Int. J. Syst. Bacteriol. 23:83-108.

5. Sneath, P. H. A., and R. Johnson. 1972. The influence on numerical taxonomic sinilarities of errors in microbiological tests. J. Gen. Microbiol. 72:377-392.

6. Wayne, L. G., T. M. Dietz, C. Gernez-Rieux, P. A. Jenkins, W. Käppler, G. P. Kubica, J. B. G. Kwapinski, G. Meissner, S. R. Pattyn, E. H. Runyon, K. H. Schröder, V. A. Silcox, A. Tacquet, M. Tsukamura, and E. Wolinsky. 1971. A co-operative numerical analysis of scotochromogenic slowly growing mycobacteria. J. Gen. Microbiol. 66:255-271.

7. Wayne, L. G., and J. R. Doubek. 1964. The role of air in the photochromogenic behaviour of $\mathrm{Myco}$. bacterium kansasii. Amer. J. Clin. Pathol, 42:431433.

8. Wayne, L. G., and J. R. Doubek. 1968. Diagnostic key to mycobacteria encountered in clinical laboratories. Appl. Microbiol. 16:925-931. 